\title{
Antimycotal Activity of Collimonas Isolates and Synergy-Based Biological Control of Fusarium Wilt of Tomato
}

\author{
Hung K. Doan, ${ }^{1}$ Nilesh N. Maharaj, ${ }^{1}$ Kaitlyn N. Kelly, ${ }^{1}$ Eugene M. Miyao, ${ }^{2}$ R. Michael Davis, ${ }^{1}$ and Johan H. J. Leveau ${ }^{1, \dagger}$ \\ ${ }^{1}$ Department of Plant Pathology, University of California, One Shields Avenue, Davis, CA 95616 \\ ${ }^{2}$ University of California Cooperative Extension, Woodland, CA 95695
}

Accepted for publication 6 September 2019.

\section{ABSTRACT}

In a continued effort to discover microorganisms with plantprotective properties, we characterized a collection of bacterial isolates from multiple geographic origins and belonging to the genus Collimonas, for their ability to inhibit in vitro the growth of a wide range of plant-pathogenic fungi and oomycetes. Isolate Collimonas arenae Cal35 showed the greatest all-round performance and was the single-best inhibitor of several of the tested pathogens, including Fusarium oxysporumf. sp. lycopersici, the causal agent of Fusarium wilt of tomato. In greenhouse trials, neither $C$. arenae $\mathrm{Cal} 35$ nor the control treatment, i.e., the commercially available Bacillus-based biofungicide Serenade Soil, was able to prevent symptom formation on tomato plants challenged with $F$. oxysporum f. sp. lycopersici. However, a mixture of Cal35 and Serenade Soil (referred to as Collinade) significantly reduced vascular discoloration and $F$. oxysporum f. sp. lycopersici-induced loss of shoot dry weight. In replicated field experiments, a Collinade application reduced vascular symptoms as well as the relative abundance of $F$. oxysporum in the root endosphere of $F$. oxysporum f. sp. Iycopersicichallenged plants. We discuss the emerging property of "biocombicontrol" by Collimonas and Bacillus in the context of synergy-based formulations for the protection of crops against pathogens.

Keywords: antifungal, anti-oomycetal, biocombicontrol, biocontrol, Collimonas arenae, endophytes, Fusarium oxysporum f. sp. lycopersici, Fusarium wilt, microbial community, phyllosphere, rhizosphere, synergy, tomato
Since their original discovery in dune soils on the Dutch island of Terschelling (de Boer et al. 1998), bacterial isolates belonging to the genus Collimonas (Leveau et al. 2010) have been reported from many other parts of the world and from a wide variety of natural environments (Axelrood et al. 2002; Chow et al. 2002; Hakvåg et al. 2009; Männistö and Häggblom 2006; Offre et al. 2008; Postma et al. 2008; Shcherbakov et al. 2013; Uroz et al. 2014; Woźniak et al. 2018). Currently, the genus Collimonas (Proteobacteria, Betaproteobacteria, Burkholderiales, Oxalobacteraceae) includes

\section{Corresponding author: J. Leveau; jleveau@ucdavis.edu}

Funding: Funding for this research came from the California Tomato Research Institute (CTRI)

*The $e$-Xtra logo stands for "electronic extra" and indicates that five supplementary figures and three supplementary tables are published online.

The author(s) declare no conflict of interest.

The authors declare that the research reported here was conducted in the absence of any commercial or financial relationships that could be construed as a potential conflict of interest. J. H. J. Leveau and H. K. Doan are both listed as inventors on patent number US 9,485,994 B2 (issued 8 November 2016) for which the research reported here served as a basis.

(C) 2020 The American Phytopathological Society four species: C. fungivorans, C. pratensis, $C$. arenae, and C. anthrihumi (de Boer et al. 2004; Höppener-Ogawa et al. 2008; Lee 2018). Members of this genus have antifungal (de Boer et al. 1998; Deveau et al. 2015; Mela et al. 2011; Senechkin et al. 2013; Wu et al. 2016), mycophagous (de Boer et al. 2001), chitinolytic (Leveau et al. 2006; Fritsche et al. 2008), and mineral weathering (Postma et al. 2010; Uroz et al. 2009) properties. The isolate best characterized to date is $C$. fungivorans Ter331 (Ter331): its genome and transcriptome have been extensively studied (Leveau et al. 2004; Mela et al. 2008, 2011, 2012), and its genes coding for chitinolysis (Fritsche et al. 2008) and for biosynthesis of the antifungal compound collimomycin (Fritsche et al. 2014; Kai et al. 2018) have been described in detail. Also, Ter331 was shown to be rhizosphere-competent in greenhouse experiments and to protect tomato plants from developing symptoms upon infection with Fusarium oxysporum f. sp. radicis-lycopersici, the cause of Fusarium crown and root rot of tomato (Kamilova et al. 2007). This and other independent observations of disease-suppressive properties of collimonads (Senechkin et al. 2013; Zhang et al. 2018) have made Collimonas bacteria a subject of interest for the biological control of fungal pathogens of plants.

It has been recognized that substantial variation exists among Collimonas species and strains in their ability to inhibit fungi (Ballhausen et al. 2016; de Boer et al. 1998) and that this variation 
has a genomic basis (Song et al. 2015). To further explore the breadth of this collimonal diversity, specifically in the context of exploitable antifungal and biocontrol properties, we launched a survey in 2009 that was dubbed Project Collifornia and led to the isolation of Collimonas strains from California soils (Uroz et al. 2014). As part of the functional characterization of these isolates, which included C. arenae Cal35 (Cal35) (Wu et al. 2015), we performed, as described here, an in-depth comparison in terms of their antimycotal activity in vitro. This activity is defined as the ability to inhibit the mycelial growth of plant-pathogenic representatives from the Eumycota (true fungi) and Oomycota (oomycetes or water molds). We demonstrated that Cal35 was the most effective antagonist in these plate-based confrontation assays. We conducted greenhouse and field experiments with this strain to assess its ability to reduce, by itself or in combination with a commercial biocontrol product, root colonization and symptom formation by the soilborne wilt pathogen F. oxysporum f. sp. lycopersici on tomato plants. This study contributes to our understanding of the phytobiome as a complex network of interactors that can be augmented or manipulated to induce emerging properties that provide plants with protection from pathogens (Bell et al. 2019; Rahman et al. 2018).

\section{MATERIALS AND METHODS}

Microorganisms used in this study. Bacteria, fungi, and oomycetes used in this study are listed in Tables 1 and 2, respectively. Collimonas strains Ter6, Ter10, Ter14, Ter91, and Ter331 have all been described elsewhere (de Boer et al. 1998, 2004; Höppener-Ogawa et al. 2008). Collimonas strains Cal1 and $\mathrm{Cal} 2$ were isolated from soil near Berry Creek, CA, whereas Cal31, $\mathrm{Cal} 35$, and Cal39 were isolated from forest soil at the Jug Handle State Natural Reserve in Mendocino County, CA (Uroz et al. 2014). An additional Collimonas strain, Collimonas sp. D-25, was provided by Yoichiro Hirose and was originally isolated from forest rhizosphere soil in Japan. Escherichia coli TOP10 (Invitrogen) and Pseudomonas putida 1290 (Leveau and Lindow 2005) were used as non-Collimonas controls. Plant-pathogenic fungi and oomycetes were provided by various faculty members in the Department of Plant Pathology at UC Davis. Most of these pathogens cause disease on economically important crops and trees. For greenhouse and field experiments with $F$. oxysporum f. sp. lycopersici, two strains of $F$. oxysporum f. sp. lycopersici race 3 were used. Strain D11 was originally isolated in 2010 from a commercial field in Yolo County, CA, and strain D12 in 2012 from San Joaquin County, CA. Isolation of D11 and D12 was achieved by washing stems of diseased tomato plants with antibacterial hand soap (Dial Gold, Henkel AG \& Company, Düsseldorf, Germany) and cutting diagonally to produce $0.25-\mathrm{cm}$-thick pieces that were surface-sterilized in $0.6 \%$ sodium hypochlorite (10\% bleach) for $1 \mathrm{~min}$ and placed on acidified potato dextrose agar (APDA) plates at $25^{\circ} \mathrm{C}$ with an 8 -h photoperiod (48W fluorescence light bulbs, Lights of America, model 8045E, Los Angeles, CA). After 5 days, hyphal tips of colonies presenting Fusarium-like conidia were transferred to fresh APDA plates and incubated for another 7 days. From the resulting colonies, single spores were transferred to individual APDA plates. To confirm membership to the genus Fusarium, DNA was extracted from $30 \mathrm{mg}$ of hyphal mass with the DNeasy Plant Mini Kit (Qiagen, Valencia, CA) and used in a PCR with Fusarium-specific primers EF-1 (5'-ATGGGTAAGGAAGACAAGAC-3') and EF-2 (5'-GGAAGTACCAGTGATCATGTT-3') (O'Donnell et al. 1998). The PCR was conducted in final reaction volumes of $50 \mu \mathrm{l}$, using $10 \mathrm{ng}$ of template DNA, $0.2 \mathrm{mM}$ of each dNTP, $0.2 \mu \mathrm{M}$ of each primer, and 0.25 units of GoTaq DNA polymerase. The following PCR cycling conditions were used: 40 cycles of
$30 \mathrm{~s}$ at $95^{\circ} \mathrm{C}, 30 \mathrm{~s}$ at $55^{\circ} \mathrm{C}$, and $1 \mathrm{~min}$ at $72^{\circ} \mathrm{C}$, and then followed by $5 \mathrm{~min}$ at $72^{\circ} \mathrm{C}$. PCR products were visualized on $1.5 \%$ agarose gels. Tests to confirm $F$. oxysporum f. sp. lycopersici pathogenicity and race differentiation were performed with tomato cultivars Early Pak 7 (susceptible), VFN-8 (resistant to race 1), Walter (resistant to race 1 and 2), and CXD 282 (resistant to race 1, 2 , and 3).

Confrontation assays. To test the antagonistic activity of Collimonas strains $(n=11)$ and non-Collimonas controls $(n=2)$ against the full set of fungi and oomycetes $(n=22)$, we used a confrontation setup that has been described previously by Mela et al. (2011). This assay involved streaking the bacteria against spores or an agar plug of fungus or oomycete on water yeast agar (WYA) supplemented with $2 \mathrm{mM} N$-acetylglucosamine (NAG). To score the antagonistic activity of each bacterial strain against each fungus/oomycete, we used a scoring system that rates the interaction on a scale from 1 to 5 , where 1 represents complete inhibition and 5 represents complete lack of inhibition (Supplementary Fig. S1). In total, we evaluated 286 pairwise confrontations (13 bacterial strains $\times 22$ fungal/oomycetal strains). Each confrontation assay was performed in triplicate, and a mean score was calculated for each pair. To calculate an antimycotal score for any given bacterial strain, we averaged the mean scores over all 22 fungi/oomycetes tested against that strain. To calculate a Collimonas-susceptibility score for any given fungus/oomycete, we averaged the mean scores over all 11 Collimonas strains tested against that fungus/oomycete. Principal component analysis was done on the antimycotal score and the Collimonas-susceptibility score using the "prcomp" function in R, version 3.1.1.

Greenhouse experiments. In total, we performed five greenhouse trials (labeled 1 through 5) to test the extent to which either C. arenae $\mathrm{Cal} 35$ or the commercially available biocontrol product Serenade Soil (AgraQuest, Davis, CA; now Bayer CropScience; active ingredient Bacillus subtilis QST713), or a mixture of Cal35 and Serenade Soil (referred to here as Collinade), reduced the shoot weight loss and vascular discoloration that resulted from

TABLE 1

Bacterial strains used in this study and tested for inhibition of mycelial growth

\begin{tabular}{llc}
\hline Species & Strain & Score $^{\mathrm{a}}$ \\
\hline Collimonas arenae & Cal35 & $1.75 \pm 0.89$ \\
\hline Collimonas fungivorans & Ter14 & $2.06 \pm 0.99$ \\
\hline Collimonas fungivorans & Ter6 & $2.30 \pm 1.01$ \\
\hline Collimonas fungivorans & Cal2 & $2.30 \pm 1.21$ \\
\hline Collimonas fungivorans & Cal1 & $2.37 \pm 1.12$ \\
\hline Collimonas fungivorans & Cal39 & $2.47 \pm 1.11$ \\
\hline Collimonas pratensis & Ter91 & $2.75 \pm 1.12$ \\
\hline Collimonas arenae & Ter10 & $2.84 \pm 1.00$ \\
\hline Collimonas pratensis & D-25 & $2.90 \pm 1.59$ \\
\hline Collimonas fungivorans & Ter331 & $2.91 \pm 1.10$ \\
\hline Collimonas pratensis & Cal31 & $3.04 \pm 1.10$ \\
\hline Pseudomonas putida & 1290 & $4.97 \pm 0.10$ \\
\hline Escherichia coli & TOP10 & $4.98 \pm 0.07$ \\
\hline
\end{tabular}

a Shown is the mean antimycotal score ( \pm standard deviation) for each bacterial strain tested. Mean scores were calculated as the average of individual antimycotal scores of each bacterial strain against all 22 tested fungi/oomycetes (Supplementary Table S1). Strains are ranked according to their score: 1 indicates complete inhibition, whereas 5 indicates not able to inhibit at all. 
challenging tomato seedlings with $F$. oxysporum f. sp. lycopersici $\mathrm{D} 11$ or D12. To this end, $F$. oxysporum f. sp. lycopersici suspensions of $10^{6}$ conidia per $\mathrm{ml}$ were prepared as described in detail elsewhere (Doan and Davis 2014). C. arenae Cal35 was streaked from a $-80^{\circ} \mathrm{C}$ freezer stock onto King's B agar and incubated at $24^{\circ} \mathrm{C}$ for 5 days, after which plates were flooded with $15 \mathrm{ml}$ of autoclaved deionized water and bacterial biomass was scraped off with a sterile glass slide. The optical density at $600 \mathrm{~nm}\left(\mathrm{OD}_{600}\right)$ was measured using a Genesys 10S UV-Vis spectrophotometer (Thermo Scientific, Wilmington, DE) and adjusted to $10^{6}$ cells per $\mathrm{ml}$ using autoclaved deionized water. Suspensions of Serenade Soil were prepared by 1,000-fold dilution of the liquid product (containing $10^{9}$ colony forming units of Bacillus per gram, as per the label) in water. Collinade was prepared by mixing equal volumes of the Serenade Soil suspension and the $C$. arenae Cal35 suspension.

TABLE 2

Fungi and oomycetes used in this study and their mean susceptibility to Collimonas

\begin{tabular}{|c|c|}
\hline Species $^{a}$ & Score ${ }^{b}$ \\
\hline Phytophthora cactorum ${ }^{1}$ & $4.00 \pm 0.00$ \\
\hline Fusarium circinatum $^{2}$ & $3.91 \pm 0.30$ \\
\hline Mucor sp. ${ }^{3}$ & $3.46 \pm 0.69$ \\
\hline Fusarium oxysporum ${ }^{4}$ & $3.27 \pm 0.65$ \\
\hline Pythium ultimum ${ }^{5}$ & $3.17 \pm 1.16$ \\
\hline Pythium violae ${ }^{6}$ & $3.14 \pm 1.28$ \\
\hline Rhizoctonia solani $^{7}$ & $3.09 \pm 0.92$ \\
\hline Phytophthora capsici ${ }^{8}$ & $3.09 \pm 0.94$ \\
\hline Colletotrichum acutatum ${ }^{9}$ & $2.84 \pm 0.81$ \\
\hline Alternaria alternata $^{10}$ & $2.77 \pm 0.66$ \\
\hline Magnaporthe grisea $^{11}$ & $2.76 \pm 0.73$ \\
\hline Aspergillus carbonarius $^{12}$ & $2.50 \pm 1.06$ \\
\hline Botryosphaeria stevensii ${ }^{13}$ & $2.36 \pm 1.11$ \\
\hline Pythium irregulare ${ }^{14}$ & $2.36 \pm 1.13$ \\
\hline Verticillium dahliae ${ }^{15}$ & $2.33 \pm 0.92$ \\
\hline Sclerotium rolfsiii ${ }^{16}$ & $2.27 \pm 0.91$ \\
\hline Cryphonectria parasitica $^{17}$ & $1.91 \pm 0.79$ \\
\hline Sclerotium cepivorum ${ }^{18}$ & $1.64 \pm 1.12$ \\
\hline Aspergillus niger $^{19}$ & $1.42 \pm 0.55$ \\
\hline Geotrichum candidum ${ }^{20}$ & $1.05 \pm 0.17$ \\
\hline Botrytis cinerea $^{21}$ & $1.04 \pm 0.13$ \\
\hline Monilinia fructicola ${ }^{22}$ & $1.00 \pm 0.00$ \\
\hline
\end{tabular}

a Fungal/oomycetal species are causative agent of the following: ${ }^{1}$ root rots; ${ }^{2}$ pitch canker of pine; ${ }^{3}$ not applicable: common soil fungus; ${ }^{4}$ Fusarium oxysporumf. sp. lycopersici, race 3 , tomato wilt; ${ }^{5}$ damping off disease of carrot; ${ }^{6}$ cavity spot of carrot; ${ }^{7}$ damping off disease; ${ }^{8}$ rot of bell pepper; ${ }^{9}$ fruit rot; ${ }^{10}$ tomato mold; ${ }^{11}$ rice blast; ${ }^{12}$ sour rot of grape; ${ }^{13}$ tree cankers; ${ }^{14}$ damping off disease of carrot; ${ }^{15}$ Verticillium wilt of tomato; ${ }^{16}$ Southern blight; ${ }^{17}$ chestnut blight; ${ }^{18}$ Allium root rot; ${ }^{19}$ not applicable: strain CBS120.49; ${ }^{20}$ sour rot on fruit and vegetables; ${ }^{21}$ bunch rot of grape; and ${ }^{22}$ brown rot of peach.

b Shown is the mean Collimonas susceptibility score $( \pm$ standard deviation) for each fungal/oomycetal species tested. Mean scores were calculated as the average of individual Collimonas susceptibility scores of each fungal/oomycetal species against all 11 tested Collimonas strains (Supplementary Table S1). Fungal/oomycetal species are ranked according to their score: 5 indicates not inhibited at all, whereas 1 indicates complete inhibition.
Following industry practices, tomato seeds (Early Pak 7) were treated with $1 \%$ hydrochloric acid for 15 to $20 \mathrm{~min}$ and rinsed three times with water (Schwarz et al. 2014). Treated seeds were sown in the greenhouse in containers with UC potting soil mix $(50 \%$ sphagnum peat moss, $50 \%$ washed sand, and per cubic meter- $2.43 \mathrm{~kg}$ of dolomite lime, $0.872 \mathrm{~kg}$ of oyster shell lime, $0.872 \mathrm{~kg}$ of superphosphate, $0.344 \mathrm{~kg}$ of calcium nitrate, $135 \mathrm{ml}$ of potassium nitrate, and $90 \mathrm{ml}$ of potassium sulfate). After 11 days, seedlings (two true leaves) were gently removed from the soil, root-dipped for $4 \mathrm{~min}$ in either water, Cal35 suspension, Serenade Soil suspension, or Collinade, and then transferred to fresh UC potting soil mix in 4in-diameter pots (one seedling per pot), and returned to the greenhouse. In trials 3 and 4, we only dipped roots in water or Collinade, not Cal35 by itself or Serenade Soil by itself. Plants were placed in a randomized complete block design, with six replicates per treatment in trial 1, 10 replicates in trials 2, 3, and 4, and 15 replicates in trial 5. Trial 1 was started in May 2012, trial 2 in July 2012, trial 3 and 4 simultaneously in December 2012, and trial 5 in 2013. After 1 week, seedlings were removed from the soil again and their roots were dipped for $4 \mathrm{~min}$ in either water or $F$. oxysporum $\mathrm{f}$. sp. lycopersici conidial suspension (strain D11 for trials 1 and 3, strain D12 for trials 2, 4, and 5) and then transplanted into containers with fresh UC potting soil mix. After 3 days, $100 \mathrm{ml}$ of water, Cal35 suspension (only in trials 1, 2, and 5), Serenade Soil suspension (only in trials 1, 2, and 5), or Collinade was poured onto the soil surrounding the crown of the tomato plant (corresponding with the root-dip treatment: for example, plants that were previously root-dipped in Collinade received a Collinade drench). One week later, this drench was repeated. Four weeks after the root inoculation with $F$. oxysporum $\mathrm{f}$. sp. lycopersici, individual tomato plants were cut at the soil line to determine shoot dry weight and to assess vascular discoloration in the stem on a scale from 0 to 4 , where 0 means no vascular discoloration and 4 means $>50 \%$ discoloration, typically dark brown (Supplementary Fig. S2). Data were analyzed using SAS version 9.4 (SAS Institute, Inc., Cary, NC), using the general linear model, two-way analysis of variance (ANOVA), and one-way ANOVA options.

Field trial. We designed and carried out two field trials (one in 2014, a second in 2015) at the Plant Pathology Department research farm at UC Davis. Hydrochloric acid-treated tomato seeds (Heinz 5508 , resistant to $F$. oxysporum f. sp. lycopersici race 1 and 2 but not race 3; also resistant to Verticillium dahliae race 1, root knot nematode, and tomato spotted wilt virus) were sown in 128-cell seedling trays $(3.5 \times 3.5 \times 6.5 \mathrm{~cm})$ and kept in the greenhouse for 3 weeks, at which time trays were immersed for $4 \mathrm{~min}$ in one of the following four suspensions (prepared as described above): (i) water (control), (ii) Cal35, (iii) Serenade Soil, and (iv) Collinade. Dipped trays were placed back in the greenhouse and after 1 week, tomato plants were transplanted by hand (17 May 2014) or mechanically (8 May 2015) into the field at $30-\mathrm{cm}$ spacing between transplants. The field featured single-row $(92-\mathrm{cm})$ beds, separated by $60-\mathrm{cm}$ between-row spacing, plus a pair of border rows. In 2014, it was set up as a randomized complete block design (four replicates) with 20 plots of 30 plants each (eight plots with water-dipped seedlings, four plots with Cal35, four plots with Serenade Soil, and four plots with Collinade). In 2015, the same part of the field was used for 40 plots of 30 plants each (eight replications; 16 plots with waterdipped seedlings, eight with Cal35, eight with Serenade Soil, and eight with Collinade). Immediately after planting, 2.5 liters of F. oxysporum f. sp. lycopersici D12 spore suspension (prepared as described above) was delivered through soil-surface located drip-irrigation tape to each plot, except for half of the plots planted with water-dipped seedlings (the water control or "no $F$. oxysporum f. sp. lycopersici" treatment). After 1 week, 10 liters of water, Cal35 suspension, Serenade Soil suspension, or Collinade were 
drip-delivered into each of the corresponding, like-treatment plots. One week later, this delivery was repeated. The plants were irrigated as needed through the drip system. Fertilizer UAN-32 (16.5\% urea $\mathrm{N}, 7.75 \%$ nitrate $\mathrm{N}$, and $7.75 \%$ ammoniacal $\mathrm{N}$ ) was applied through the drip at $75 \mathrm{ml}$ per plot once a week for the 2014 growing season and once every 2 weeks for the 2015 growing season, starting 12 days after transplanting until flowering. Plants also received a one-time application of Miracle-Gro Quick Start (Scotts MiracleGro, Marysville, OH) 5 days after transplanting, at $450 \mathrm{ml}$ per plot. Weeding was done manually. Dusting sulfur (Integrated Agribusiness Professionals, Fresno, CA) was applied with a hand-held rotary duster at a rate of approximately $22 \mathrm{~kg}$ per acre during fruit set to control powdery mildew and russet mites. Tomato fruit were hand-harvested on 19 September 2014 and on 9 September 2015 (approximately 4 months after planting in each case), at which time more than $90 \%$ of the fruit were ripe. Vascular discoloration and shoot dry weight (after removal of the fruit, see below) were determined for 15 plants in the center of each plot, as described above, and averaged per plot (four plots in 2014, eight plots in 2015). From these same 15 plants per plot, the red, green, sunburn, and moldy fruit were collected, weighed, and averaged per category. Marketable yield was calculated from red fruit weight in each plot and expressed in U.S. tons per acre (which can be converted to megagrams per hectare by multiplication by 2.2417 ). Data were analyzed using SAS version 9.4 (SAS Institute), using the general linear model, and two-way ANOVA, and one-way ANOVA options. Where significant $F$ values were obtained, the significance of mean differences was assessed using Tukey's honest significant difference test at $P=0.05$.

Soil and root sampling and DNA extraction. At five time points during the 2015 field trial growing season (7 July, 20 July, 3 August, 19 August, and 1 September), we collected soil and root material from six plants each from two treatments $(F$. oxysporum $\mathrm{f}$. sp. lycopersici only and $F$. oxysporum f. sp. lycopersici plus Collinade) for microbial community profiling. Plant roots were carefully collected while leaving the majority of the tap and lateral roots intact, and transported to the laboratory where loosely adhering soil was removed from each root by hand loosening and vigorous shaking. From these roots, rhizosphere soil was collected by brushing the root surface with a clean 3-in-wide paint brush. Root debris was removed by passing the soil through a 1-mm sieve. Rhizoplane soil was collected by cutting a 3 -cm-long root bundle, $2 \mathrm{~cm}$ past the first lateral roots, washing this root cutting under running tap water for $20 \mathrm{~s}$, vortexing for $20 \mathrm{~s}$ in a 50-ml Falcon tube filled with wash buffer (Rastogi et al. 2010) to an adjusted volume of $45 \mathrm{ml}$, sonicating in a Branson water bath for $7 \mathrm{~min}$, and vortexing again for $20 \mathrm{~s}$. After removal of the root material, the root wash was centrifuged for $7 \mathrm{~min}$ at $7,197 \times g$. The supernatant was discarded and the pellet frozen at $-20^{\circ} \mathrm{C}$ until DNA extraction. We also collected the microbial community of the tomato root endosphere by washing the previously sonicated roots twice more, air drying these roots for $1 \mathrm{~h}$, and grinding them in liquid nitrogen (a 3mm-thick cross section taken at the root bundle midpoint) into a fine powder using mortar and pestle. DNA extractions from soil were done using the PowerSoil DNA Isolation Kit (Mo Bio Labs, cat. \# 12888) on $250 \mathrm{mg}$ of soil per extraction. Microbial DNA was extracted from plant roots (approximately $60 \mathrm{mg}$ root tissue per extraction) using the PowerPlant Pro DNA Isolation Kit (Mo Bio Labs, cat. \# 13400-50).

PCR amplification, sequencing, and analysis of bacterial and fungal DNA from soil and root samples. DNA extracts were diluted 10-fold and used as template in a PCR to amplify bacterial and fungal small subunit ribosomal RNA sequences. For the bacterial community, we used primers $799 \mathrm{~F}$ and $1193 \mathrm{R}$
(Bodenhausen et al. 2013; Chelius and Triplett 2001) to amplify the V5 to V7 region of the bacterial 16S rRNA gene. Samples were multiplexed by barcoding of the 799F forward primer linked by AG to an 8-bp hamming barcode (Aleklett et al. 2015; Hamady et al. 2008). PCR was done using GoTaq Green Master Mix (Promega, cat. \# M7122). For this, $15 \mu \mathrm{l}$ reactions were set up as follows: $7.5 \mu \mathrm{l}$ of $2 \times$ GoTaq Green master mix; $3.9 \mu \mathrm{l}$ of water; $0.3 \mu \mathrm{l}$ of reverse primer $(10 \mu \mathrm{M}) ; 0.3 \mu \mathrm{l}$ of bovine serum albumin $(20 \mathrm{mg} / \mu \mathrm{l}$; NEB cat. \# B9000S); $1.5 \mu \mathrm{l}$ of forward primer $(2 \mu \mathrm{M})$; and $1.5 \mu \mathrm{l}$ of template DNA. Cycling conditions were as follows: initial denaturation at $94^{\circ} \mathrm{C}$ for $2 \mathrm{~min}$, and then 35 cycles of denaturation at $94^{\circ} \mathrm{C}$ for $30 \mathrm{~s}$, primer annealing at $55^{\circ} \mathrm{C}$ for $30 \mathrm{~s}$, product extension at $72^{\circ} \mathrm{C}$ for $1 \mathrm{~min}$, and final extension at $72^{\circ} \mathrm{C}$ for $10 \mathrm{~min}$. Amplicons were visualized on a $1 \%$ agarose gel, pooled, and run again on a $0.6 \%$ gel to achieve separation of the 430-bp bacterial rRNA amplicon band which was excised from gel and purified using the Zymoclean Gel DNA Recovery Kit (Zymo Research, cat. \# D4007), and then submitted for library preparation and sequencing at the DNA Technologies Core at the UC Davis Genome Center. Sequencing was performed on Illumina's MiSeq paired end $300 \times 300$ bp platform. For the fungal community, we amplified by PCR the ITS1 (internal transcribed spacer 1) regions using primers BITS1 and B58S3 with barcodes built into the forward primer (Bokulich and Mills 2013). The PCR recipe was the same as above. The cycling conditions were as follows: initial denaturation at $95^{\circ} \mathrm{C}$ for $2 \mathrm{~min}, 35$ cycles of denaturation at $95^{\circ} \mathrm{C}$ for $30 \mathrm{~s}$, primer annealing at $55^{\circ} \mathrm{C}$ for $30 \mathrm{~s}$, product extension at $72^{\circ} \mathrm{C}$ for $1 \mathrm{~min}$, and final extension at $72^{\circ} \mathrm{C}$ for $5 \mathrm{~min}$. The amplicons were visualized and pooled as described above. The amplicon pool was purified using the QIAquick PCR Purification Kit from Qiagen (cat. \# 28104), and then submitted for library preparation and sequencing as described above. Illumina DNA sequences were processed and analyzed using QIIME version 1.9.1 (Caporaso et al. 2010). For the bacterial community, paired reads were joined using join_ paired_ends.py; barcodes extracted using extract_barcodes.py; reads quality filtered and demultiplexed using split_libraries_ fastq.py $-\mathrm{q}$ 19. Operational taxonomic units (OTUs) were picked at $97 \%$ similarity using pick_open_reference_otus.py - s 0.1 ; chimeras identified using chimera slayer parallel_ identify_chimeric_seqs.py and removed using filter_fasta.py, filter_alignment.py, make_phylogeny.py, make_otu_table.py, filter_otus_from_otu_table.py, and biom add-metadata. The OTU table was filtered to remove OTUs that constituted less than $0.005 \%$ of all reads using filter_otus_from_otu_table.pymin_count_fraction 0.00005. Samples containing less than 1000 reads were dropped from the analysis. For the fungal community, sequence processing was done as described above with the following exceptions: paired ends were not joined (join_ paired_ends.py unable to pair reads from 180 to 220 bp amplicons), chimeras were not identified (chimera slayer does not work on ITS sequences), and taxonomy was assigned using RDP Classifier with the UNITE database (Ver. 7, 2015-08-01, developer files) (Kõljalg et al. 2013). Beta diversity comparisons were run using jackknifed_beta_diversity.py with the Bray-Curtis dissimilarity, and the weighted and unweighted unifrac (bacteria only) metrics. Cluster significance was tested using the Adonis test in compare categories.py. The OTU table was rarefied to 1,000 counts and analyzed in R (R Core Team 2014). Relative abundances of taxa that include representatives known as soilborne pathogens of tomato (i.e., F. oxysporum, F. solani, V. dahliae, Plectosphaerella cucumerina, Rhizoctonia solani, Pyrenochaeta lycopersici, and Colletotrichum coccodes) were log-transformed, averaged by root/ soil compartment and sampling time point, compared between the two treatments $(F$. oxysporum $\mathrm{f}$. sp. lycopersici only and $F$. oxysporum 
f. sp. lycopersici plus Collinade) using a student's $t$ test, and reported as back-transformed averages. Graphs were produced using the ggplot2 and dplyr packages (Wickham 2009; Wickham and Francois 2015) and Excel (Microsoft).

\section{RESULTS}

In vitro antimycotal activity of Collimonas isolates. We tested 11 strains of Collimonas (Table 1) in a standardized confrontation assay (Mela et al. 2011) to assess and compare their effect on mycelial growth of 22 fungi and oomycetes, most with plantpathogenic properties (Table 2). We also included two nonCollimonas bacterial strains as controls, i.e., E. coli TOP10 and Pseudomonas putida 1290. In total, 286 bacterium-fungus/ oomycete pairs were evaluated in triplicate on WYA supplemented with 2 mM NAG as described previously (Mela et al. 2011) and scored on an 'antimycotal' scale from 1 (complete or nearcomplete inhibition of mycelial growth) to 5 (total lack of inhibition of mycelial growth) as shown in Supplementary Figure S1.

Averaged over all tested fungi/oomycetes (Table 1), the antimycotal performance was greatest for $C$. arenae $\mathrm{Cal} 35$ (score $=1.75$ ) and lowest for E. coli TOP10 and Pseudomonas putida 1290 (scores were 4.98 and 4.97, respectively). C. arenae Cal35 was unique and superior among the tested Collimonas strains in that it was the only one to achieve complete inhibition of Sclerotium rolfsii and Rhizoctonia solani as well as the oomycetes Pythium violae, Pythium ultimum, and Phytophthora capsici (Supplementary Table S1). $C$. arenae $\mathrm{Cal} 35$ also was the single best inhibitor of $F$. circinatum, $F$. oxysporum (more specifically, F. oxysporum f. sp. lycopersici), and Mucor sp. (Supplementary Table S1). The poorest-performing Collimonas strain was $C$. fungivorans Cal31 (score= 3.04): it was the weakest inhibitor of Aspergillus niger, Colletotrichum acutatum, V. dahliae, and Botrytis cinerea (Supplementary Table S1). C. pratensis D-25 had a relatively low average antimycotal score (2.90), but it was the only Collimonas isolate to completely inhibit the growth of Botryosphaeria stevensii and V. dahliae (Supplementary Table S1). Figure 1A shows a principal component analysis (PCA) plot based on the scores of individual Collimonas strains against all tested fungi/oomycetes. In this plot, the PC1 axis correlated almost perfectly $\left(R^{2}=0.9995\right)$ with the mean antimycotal score (Table 1$)$. The plot highlights the fact that taxonomy is not a good predictor of antagonist potential: for example, strains Cal35 and Ter10 both belong to $C$. arenae but differed substantially in their mean antimycotal score, whereas the two strongest inhibitors of Phytophthora capsici, namely Cal35 and D-25 (Supplementary Table S1), belong to different species (C. arenae and $C$. pratensis, respectively).

Among the tested fungi and oomycetes, the overall least impacted by Collimonas (Table 2) were Phytophthora cactorum and $F$. circinatum: the mean susceptibility scores of these two fungal species were 4.00 and 3.91, respectively, on a scale from 5 (completely unaffected by Collimonas) to 1 (complete or near-complete inhibition). Three fungi, i.e., Monilinia fructicola, Botrytis cinerea, and Geotrichum candidum were very sensitive (scores of 1.05 or lower) to all Collimonas strains tested. All three of these fungi are known as postharvest pathogens of fruit, including tomato (Doan et al. 2016). None of the tested fungi were inhibited by E. coli or Pseudomonas putida. Figure 1B shows a PCA plot based on the scores of individual fungi and oomycetes against all Collimonas strains. The PC1 values of individual fungi/oomycetes strongly correlated with their mean susceptibility scores, with the most resistant strains Phytophthora cactorum and F. circinatum to the far right on the axis. The plot also revealed clustering of species belonging to the same genus, more specifically Pythium, Sclerotium, Fusarium, Aspergillus, and Phytophthora. This may suggest that these species share the same vulnerabilities or modes of tolerance to Collimonas strains.

Greenhouse-assessed biocontrol activity of $C$. arenae Cal35. As the best-performing Collimonas strain in the confrontation assays, $C$. arenae Cal35 was selected for further experiments to test the hypothesis that its in vitro observed antifungal activity predicted the ability of Cal35 to protect tomato roots from soilborne F. oxysporum f. sp. lycopersici, when applied as prophylactic root dip and subsequent soil drenches by itself or in combination with the Bacillus-based biocontrol product Serenade Soil. To this end, we performed five greenhouse trials for which the results are shown in Figure 2 (data and statistical analysis are provided in Supplementary Table S2). In all five trials, the challenge with $F$. oxysporum f. sp. lycopersici strain D11 or D12 (Fig. 2A to D, red symbols) caused high levels of vascular discoloration (y-axis) and a reduction in shoot dry weight (x-axis), compared with the no-F. oxysporum f. sp. lycopersici control treatment (Fig. 2A to $\mathrm{D}$, green symbols). On average (Supplementary Table S2), F. oxysporum f. sp. lycopersici reduced shoot dry weight by $45 \%$ and increased the vascular discoloration score from 0 (no discoloration) to 3.79 (on a scale where scores of 3 and 4 represent 25 to $50 \%$ and $>50 \%$ discoloration, respectively). By itself, C. arenae Cal35 (tested in three of the five trials, Fig. 2A, B, and D, yellow symbols) was not able to suppress the effects of the pathogen, and neither was Serenade Soil by itself (Fig. 2A, B, and D, dark gray symbols). However, when Cal35 and Serenade Soil were applied as a 1:1 mixture (Collinade, tested in all five trials), F. oxysporum f. sp. lycopersici-evoked vascular discoloration was significantly reduced in four of the five greenhouse trials (Fig. 2A, C, and D, blue symbols), from an average score of 3.79 down to 1.72 (on a scale where 1 and 2 represent $<5 \%$ and 5 to $25 \%$ discoloration, respectively). In these same four trials, Collinade reduced the loss of shoot dry weight due to $F$. oxysporum f. sp. lycopersici, from an average of $44 \%$ (F. oxysporum f. sp. lycopersici only) to only $21 \%$ (Supplementary Table S2). Greenhouse trial 2 was the only trial that did not show an effect of Collinade (see Discussion).

Performance of Collinade in field settings. To assess whether the greenhouse results could be replicated under field conditions, we set up two controlled field trials at the Plant Pathology Department research farm at UC Davis, one in 2014 (Fig. 2E) and another in 2015 (Fig. 2F) (data in Supplementary Table S2). In both 2014 and 2015, vascular discoloration was significantly lower with the Collinade treatment $(0.98$ and 1.09 , respectively, corresponding to $<5 \%$ discoloration) than with the $F$. oxysporum $\mathrm{f}$. sp. lycopersicionly control (3.70 and 3.41, respectively, $>25 \%$ discoloration). In contrast, Cal35 by itself (2014 and 2015 mean scores of 3.15 and 3.62 , respectively) and Serenade Soil by itself (3.25 and 2.83, respectively) were not able to significantly reduce vascular discoloration (Supplementary Table S2). This mirrored the synergistic effects between Cal35 and Serenade Soil that we had observed in the greenhouse trials (Fig. 2A, C, and D). In the control plants (i.e., no $F$. oxysporum f. sp. lycopersici), the vascular discoloration score was higher in 2015 than in 2014 (1.74 and 0.08, respectively), most likely due to soilborne carryover of $F$. oxysporum f. sp. lycopersici inoculum from the 2014 experiment into 2015.

In the 2014 field trial, the largest shoot dry weight per plant was observed with the Collinade treatment (245 grams, on average). However, shoot dry weights were not statistically different between any of the treatments that year, including no- $F$. oxysporum $\mathrm{f}$. sp. lycopersici and F. oxysporum f. sp. lycopersici-only (241 and $211 \mathrm{~g}$, respectively). In the 2015 field trial (for which the number of plots per treatment was doubled from four to eight), we found a statistically significant impact of $F$. oxysporum $\mathrm{f}$. sp. lycopersici on shoot dry weight: $171 \mathrm{~g}$ with the $F$. oxysporum f. sp. lycopersici-only 
treatment compared with $240 \mathrm{~g}$ for no-F. oxysporum $\mathrm{f}$. sp. lycopersici). In this trial too, the largest shoot dry weight per plant was observed with the Collinade treatment ( $244 \mathrm{~g})$, which was greater than, but not significantly different from, Cal35 by itself (195 g) or Serenade Soil by itself (224 g) (Supplementary Table S2).

The field trials allowed us to also assess the impact of $F$. oxysporum $\mathrm{f}$. sp. lycopersici and the various treatments on marketable fruit yield, which was calculated as tons of nondefect red tomatoes harvested per acre (Fig. 3A). In both 2014 and 2015, the no- $F$. oxysporum f. sp. lycopersici control (66 and 45 tons, respectively) presented a greater yield than the $F$. oxysporum f. sp. lycopersici-only challenge (56 and 37 tons, respectively). However, these differences were statistically not significant, as were the differences with and among treatments with Cal35 by itself, Serenade Soil by itself, and Collinade (Supplementary Table S2). Among the latter three treatments, the Collinade treatment gave the highest yield in both years (66 and 44 tons, respectively) and was the only one to reduce sunburn in both years (Fig. 3B). In the Discussion, we will address this observation in the context of the impact of $F$. oxysporum f. sp. lycopersici on crop foliage. We observed no significant differences in the percentage of green or moldy fruit between any treatments in either trial (data not shown).

Fungal community composition of $F$. oxysporum f. sp. lycopersici-challenged and Collinade-treated roots. Given that (i) vascular discoloration is a response of the tomato plant to $F$. oxysporum f. sp. lycopersici infection, and (ii) Collinade treatment reduced the incidence of vascular discoloration in $F$. oxysporum f. sp. lycopersici-challenged tomato plants in both greenhouse and field (Fig. 2), we hypothesized that the abundance of $F$. oxysporum f. sp. lycopersici was lower in Collinade-treated roots of $F$. oxysporum f. sp. lycopersici-challenged tomato plants than in untreated roots of $F$. oxysporum $\mathrm{f}$. sp. lycopersici-challenged plants. To test this hypothesis, we extracted at various time points during the 2015 growing season total microbial DNA from the root endosphere, as well as rhizoplane and rhizosphere, of field-grown tomato plants for community profiling by fungal ITS sequencing. The endospheres of Collinade-treated and untreated roots both contained ITS sequences belonging to $F$. oxysporum species, which is consistent with the fact that these roots were challenged with F. oxysporum f. sp. lycopersici. Importantly, however, the average relative abundance of $F$. oxysporum sequences was significantly higher in untreated than in Collinade-treated roots (Fig. 4). Also, the percentage of roots harboring $F$. oxysporum at a relative abundance greater than $10 \%$ was higher for untreated than for Collinade-treated plants at all sampling times (Supplementary Fig. S3; Supplementary Table S3). F. oxysporum could be detected in all three root compartments (endosphere, rhizoplane, and rhizosphere) as early as 4 weeks after planting (Supplementary Fig. S4), but in the rhizoplane (i.e., on the root surface) and in rhizosphere soil at lower average abundances than in the root endosphere, and with no significant differences between Collinade-treated and untreated plants (Fig. 4, Supplementary Table S3). In the vast majority of samples, F. oxysporum was the most abundant taxon compared with other taxa that have known representatives with demonstrated ability as root pathogens of tomato (Fig. 4; Supplementary Fig. S4). These included $F$. solani (Fusarium foot root of tomato), V. dahliae (Verticillium wilt of tomato), Plectosphaerella cucumerina (tomato wilt), Rhizoctonia solani (damping off of tomato), Pyrenochaeta lycopersici (corky root of tomato), and Colletotrichum coccodes (anthracnose fruit rot, but also tomato brown root rot complex in combination with Pyrenochaeta lycopersici; Vrisman et al. 2016). Among these, Pyrenochaeta lycopersici and $C$. coccodes were the only ones with significantly different relative abundances in untreated and Collinade-treated roots (Fig. 4): both taxa showed higher representation in treated roots, and significantly so either in all compartments $(C$. coccodes) or only in the root endosphere (Pyrenochaeta lycopersici). We will interpret these findings in the Discussion, in the context of known limitations to the use of ITS sequences for fungal species assignment.

We also profiled the bacterial communities associated with the roots of tomato plants in the 2015 field trial, with the specific purpose to compare the abundances of Collimonas and Bacillus in Collinade-treated and untreated plots. Whereas Collimonas reads fell below the threshold of $0.1 \%$ (i.e., 1 read per 1,000 ) in every sample, the genus Bacillus was generally well-represented in all three root compartments (endosphere, rhizoplane, rhizosphere).
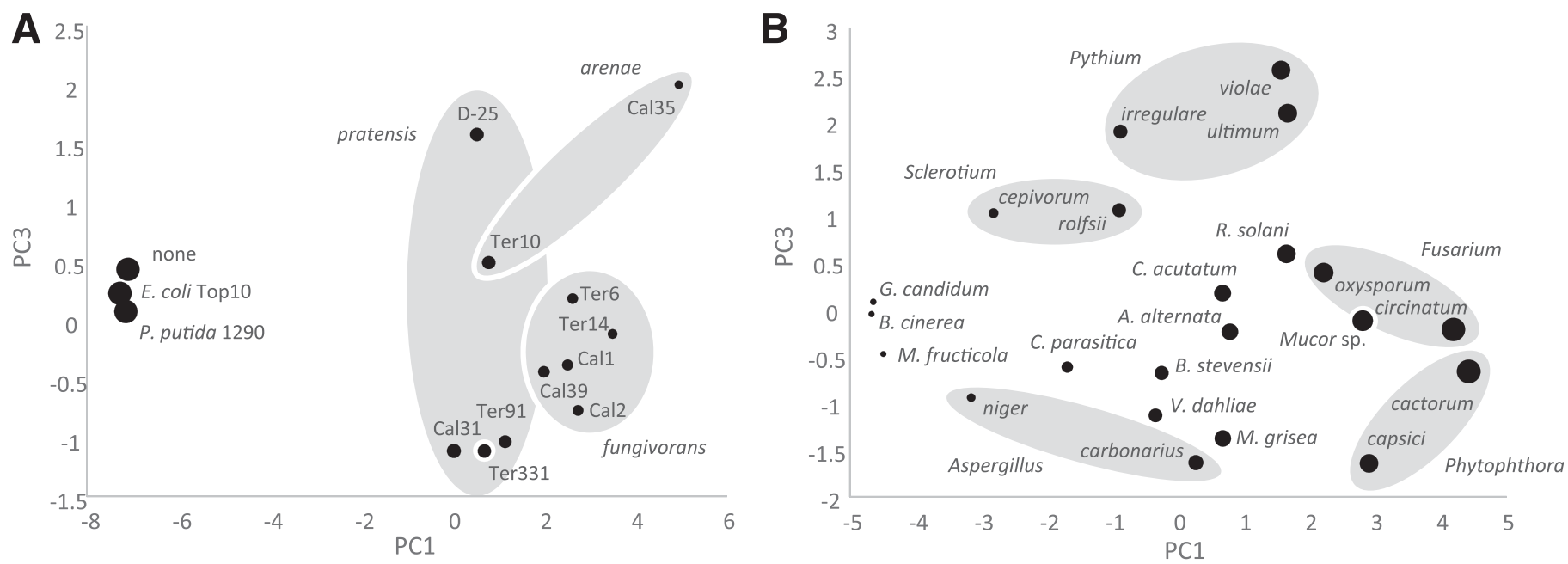

Fig. 1. Principal component analysis (PCA) showing variation in A, the ability of different bacterial strains to impact growth of fungal/oomycetal strains or $\mathbf{B}$, the growth of different fungal/oomycetal species in the presence of bacterial strains. Each data point is labeled with the strain or species it represents. Graphs were generated from inhibition scores of 286 pairwise bacterial-fungal/oomycetal confrontations on water yeast agar supplemented with $\mathrm{N}$-acetylglucosamine agar plates (described in text). More specifically, the PCA was performed on the data shown in Supplementary Table S1, organized either as columns (i.e., "antimycotal" score, to generate panel A) or as rows (i.e., "Collimonas-susceptibility" score, to generate panel B). The size of each data point is proportional to the average scores of each bacterial strain (A) or fungal/oomycetal species (B) as listed in Table 1 (A) or Table 2 $(B)$, respectively. Microorganisms belonging to the same species (panel A) or genus (panel B) are circled by the same ellipse. 
Relative abundances across the growing season were on average slightly greater in the untreated than in the Collinade-treated samples, but these differences were not significant (Supplementary Fig. S5).

\section{DISCUSSION}

We compared the antifungal and anti-oomycetal activities of Collimonas isolates from various sources and identified Californian strain $C$. arenae Cal35 as the most "all-around" effective in platebased confrontation assays against a wide range of fungi and oomycetes. Through this analysis, we discovered that Collimonas taxonomy (i.e., membership in one of the known species) was not a perfect predictor of antimycotal potential, as some strains of
C. fungivorans or $C$. arenae clearly did better than others from the same species (Table 1). A similar conclusion was reached by Ballhausen et al. (2016) who found that fungal inhibition was highly variable between members of the species $C$. pratensis. These observations suggest interspecies exchange and/or extragenus acquisition of the genes and gene clusters underlying such antifungal properties, which would be consistent with the relatively high number of genomic islands found on Collimonas genomes sequenced to date (Song et al. 2015). There were also inconsistencies between our results and those of Ballhausen et al. (2016): for example, the latter reported that strains Ter6, Ter10, Ter14, Ter91, and Ter331 lacked the ability to inhibit mycelial growth, which contradicts the results presented here and those reported in previously published studies (Fritsche et al. 2014; Garbeva et al. 2014).
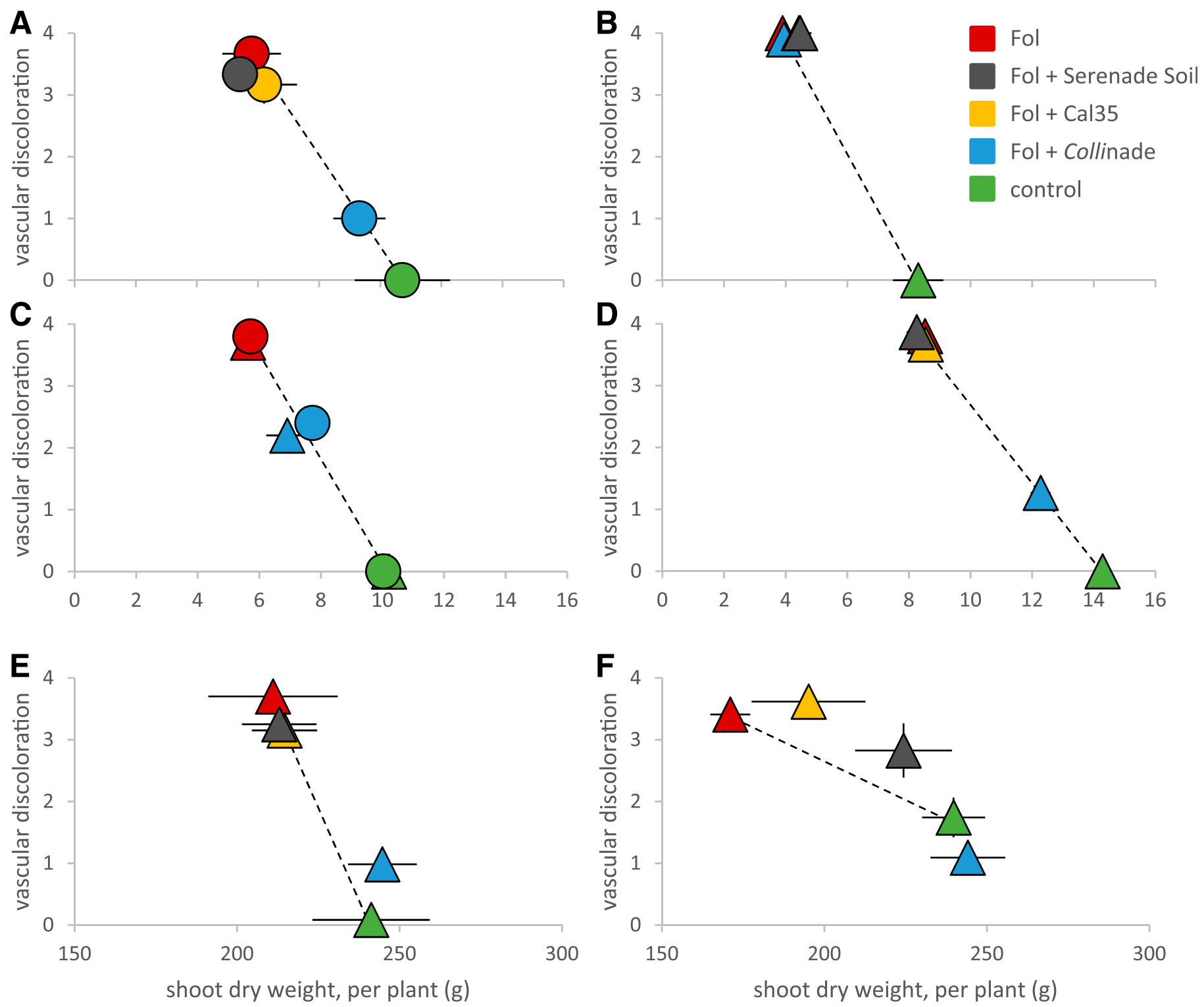

Fig. 2. Average vascular discoloration and shoot dry weight of tomato plants that were grown in the $\mathbf{A}$ to $\mathbf{D}$, greenhouse or $\mathbf{E}$ and $\mathbf{F}$, field in the presence or absence of Fusarium oxysporum f. sp. lycopersici (Fol) and treated or untreated with Collinade, Serenade Soil suspension, or Cal35 suspension. Data points are colored according to treatment. Error bars show the standard deviation. The shape of each data point refers to the strain of $F$. oxysporum f. sp. lycopersicithat was used in the experiment, i.e., D11 (circle) or D12 (triangle). A, B, and D show the results of one independent greenhouse trial, and $\mathbf{C}$ shows the results of two independent greenhouse trials, which happened concurrently, for a total of five greenhouse trials. $\mathbf{E}$ and $\mathbf{F}$ each show one replicate of the field trial, for a total of two field trials. In each panel, the $F$. oxysporum $\mathrm{f}$. sp. lycopersici-only positive control and no- $F$. oxysporum $\mathrm{f}$. sp. lycopersicinegative control are connected by a dashed line to provide reference. Note that the scale on the $x$-axis in panels $A$ to $D$ is different from that in panels $\mathrm{E}$ and F. Data for these graphs are presented in Supplementary Table S2. 
A possible explanation for this discrepancy may be a difference in medium composition of the confrontation assay: whereas Ballhausen et al. (2016) used WYA, our agar plates, as well as those used by Fritsche et al. (2014) and Garbeva et al. (2014) were WYA supplemented with NAG, which is known to stimulate antifungal activity in Collimonas (Fritsche et al. 2014; Garbeva et al. 2014). The underlying mechanism for this stimulation is not known, but the difference in outcomes serves as a powerful demonstration of the context-dependency of bacterial antifungal activity.

The superior activity of $C$. arenae $\mathrm{Cal} 35$ against $F$. oxysporum $\mathrm{f}$. sp. lycopersici on WYA-NAG plates (Supplementary Table S1) did not translate into good performance of Cal35, by itself, against

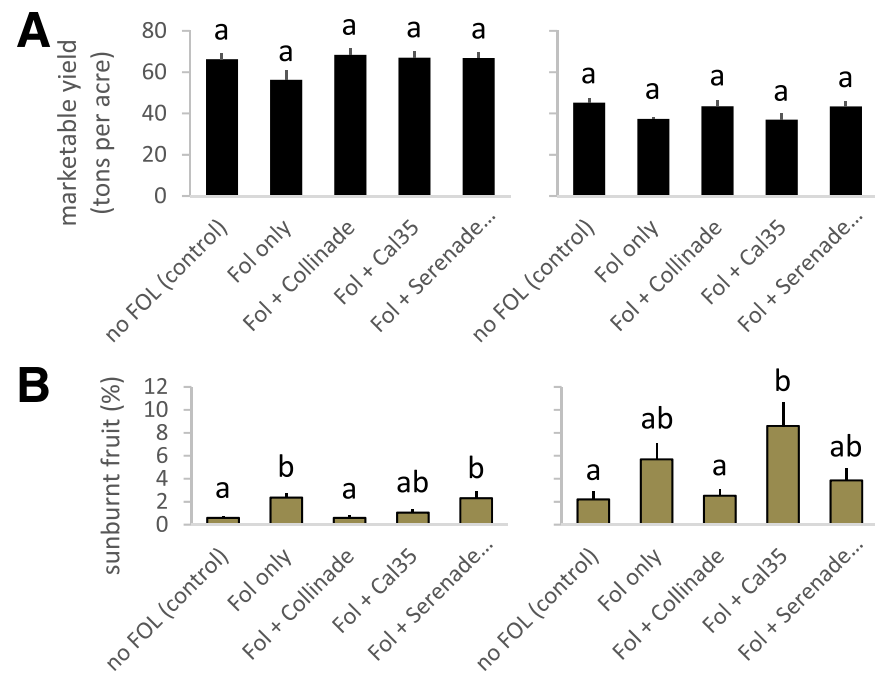

Fig. 3. Impact of various treatments on the $\mathbf{A}$, yield and $\mathbf{B}$, loss due to sunburn in field experiments performed in 2014 (left graph) and 2015 (right graph). Treatments listed on the $\mathrm{x}$-axis include a no-Fusarium oxysporum f. sp. lycopersici negative control ('no FOL') and a F. oxysporum f. sp. lycopersici-only positive control ('Fol only'). Marketable yield is expressed in tons per acre and sunburnt fruit as percentage of total harvest. Both represent averages from four plots in 2014 and eight plots in 2015. Within each year, bars with the same letter represent averages that were not significantly different from each other.
F. oxysporum f. sp. lycopersici in greenhouse or field settings (Fig. 2 ). Such a disagreement between in vitro and in vivo results is not uncommon in studies that aim to identify biocontrol agents of fungal plant diseases (Heydari and Pessarakli 2010; Knudsen and Dandurand 2014; Rilling et al. 2019). However, when C. arenae Cal35 was combined with the commercial product Serenade Soil, it was shown to significantly reduce $F$. oxysporum f. sp. lycopersiciinduced vascular discoloration in tomato plants (Fig. 2). The observation that disease control is more efficient with a mixture of two or more biocontrol agents than with single agents has been reported for a number of different crops (Chemeltorit et al. 2017; Duijff et al. 1999; Jambhulkar et al. 2018; Lemanceau et al. 1992; Liu et al. 2018; Panebianco et al. 2015; Park et al. 1988; Pierson and Weller 1994), including tomato (Domenech et al. 2006; Marian et al. 2019; Tayal et al. 2011). The greater efficacy of such mixtures is often explained as emerging from the complementarity and/or synergism between the modes of action of the agents in the mixture (Xu et al. 2011). For example, de Boer et al. (2003) reported that a mixture of two Pseudomonas putida strains reduced the incidence of Fusarium wilt of radish by both induced systemic resistance and iron sequestration. Microbes in a mixture may also occupy different spatial and nutritional niches, which can lead to exclusion of the pathogen. For example, two yeast isolates, each with a different carbon utilization profile, reduced fruit infection of apple by Penicillium expansum (Janisiewicz 1996). The mechanism underlying the activity of Collinade is currently unknown. However, based on the published traits of Collimonas, i.e., mycophagy (de Boer et al. 2001), production of antifungal compounds (Fritsche et al. 2014), rhizosphere competency (Kamilova et al. 2007), and of the active ingredient of Serenade Soil, Bacillus subtilis QST713 (Pandin et al. 2018), i.e., induced systemic resistance (Lahlali et al. 2013), antifungal compounds (Baysal et al. 2013), and rhizosphere competency (Mendis et al. 2018), it seems reasonable to hypothesize that two or more of these traits act synergistically toward suppressing $F$. oxysporum f. sp. lycopersici activity in the greenhouse. Additional studies are needed to tease out the specifics of the Collinade mode-of-action. Importantly however, our data clearly hint at the potential to improve already existing products such as Serenade Soil through supplementation with bacteria such as Collimonas to achieve what we refer to as "biocombicontrol" of plant diseases.

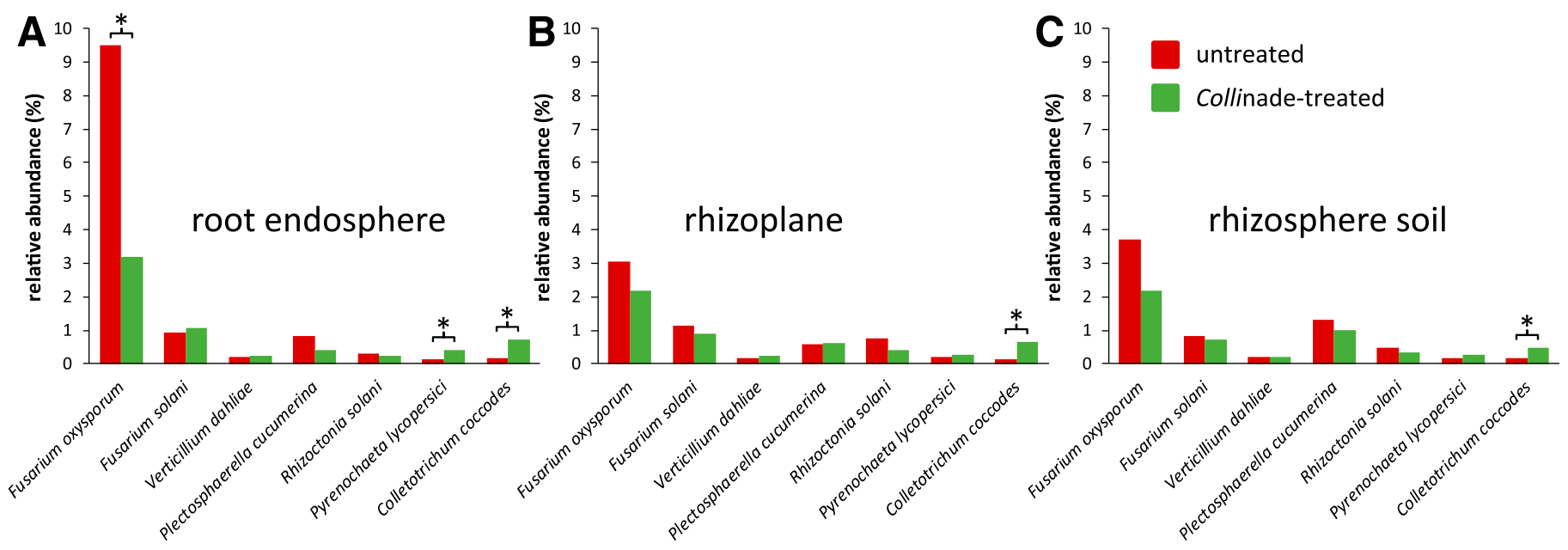

Fig. 4. Average relative abundance of Fusarium oxysporum and six other fungal taxa in, on, or near the roots of $F$. oxysporumf. sp. lycopersici-challenged tomato plants in the 2015 field trial. Data are broken down by root compartment (A, B, and $\mathbf{C}$, endosphere, rhizoplane, and rhizosphere) and treatment: Collinade-treated (green) or untreated (red). Relative abundances were derived from internal transcribed spacer amplicon sequence data as the number of reads (per 1,000 ) assigned to each of the seven different fungal taxa, and averaged over five sampling time points $(4,6,8,10$, and 12 weeks after planting). 
In one out of five greenhouse experiments, the application of the Collinade mixture failed to protect tomato plants (Fig. 2B). During this particular trial, greenhouse temperatures were higher (low/high $\left.17 / 33^{\circ} \mathrm{C}\right)$ than in any of the other greenhouse trials $\left(16 / 31^{\circ} \mathrm{C}, 15 /\right.$ $29^{\circ} \mathrm{C}, 16 / 30^{\circ} \mathrm{C}$ ). We do not know whether this caused Collinade failure in this one trial, but numerous studies have documented temperature as an important factor influencing the production of antifungal compounds by bacteria, the interaction between biocontrol agents (Fiddaman and Rossall 1993; Landa et al. 2004; Wright and Thompson 1985), growth of $F$. oxysporum f. sp. lycopersici, and stress levels of tomato plants (Clayton 1923).

Whereas Collinade was shown to significantly reduce vascular discoloration and loss of shoot weight of field-grown $F$. oxysporum $\mathrm{f}$. sp. lycopersici-challenged tomato plants (Fig. 2E and F), it did not produce significantly higher fruit yields (Fig. 3A). This is not an unexpected outcome, as it has been shown that even $F$. oxysporum $\mathrm{f}$. sp. lycopersici-challenged tomato plants can achieve relatively high marketable yields (Atkinson and Adamson 1977). The variety that was used in our field experiment, Heinz 5508, typically bears between 47 and 65 tons of fruit per acre (Miyao 2013), which is very close to what we observed in our field trials, i.e., between 56 and 69 tons per acre in 2014 and between 37 and 46 tons per acre in 2015. We attribute the lower yield in the 2015 trial to higher pathogen pressure due to residual F. oxysporum f. sp. lycopersici from the 2014 trial. Interestingly, Heinz 5508 is known for its relatively poor canopy cover, reported as between 63 and 74\% (Miyao 2013), where 80\% is typically desired to protect fruit from sunburn. We found that Collinade was the only treatment that significantly protected fruit from sunburn in both of our field trials (Fig. 3B). Collinade also was the only treatment that significantly reduced the $F$. oxysporum $\mathrm{f}$. sp. lycopersici-induced loss of shoot dry weight in both trials (Fig. 2E and F). We suspect that the two observations are linked, in that Collinade-prevented $F$. oxysporum f. sp. lycopersici-caused leaf wilting and leaf loss lowered the incidence of sunburnt fruit. Such a positive correlation between loss of foliage and fruit damage due to sun exposure has been demonstrated previously (Maharaj et al. 2018).

By profiling the microbiota of field-grown $F$. oxysporum f. sp. lycopersici-challenged tomato plants, we found that the levels of $F$. oxysporum in the root endosphere were lower in plants that were treated with Collinade than in untreated plants (Fig. 4). Treated plants also showed less vascular discoloration than untreated plants (Fig. 2). These two observations are consistent with reports that vascular discoloration is proportionate to the degree of $F$. oxysporum $\mathrm{f}$. sp. lycopersici infection in tomato roots (Corden and Chambers 1966; Rania et al. 2016). A similar correlation between Fusarium levels in plant tissue and disease severity has been reported for several other Fusarium diseases, including Fusarium crown and root rot of tomato (Validov et al. 2011), Fusarium wilt of chickpea (Jiménez-Fernández et al. 2011), and Fusarium crown rot of wheat (Hogg et al. 2007). Two other fungal taxa that were significantly impacted by the Collinade treatment in our field trial were $C$. coccodes and Pyrenochaeta lycopersici: contrary to F. oxysporum, both were on average more abundant in, on, and/or near the roots of treated plants compared with untreated plants (Fig. 4). It is unclear if this increase in relative abundance represents an indirect consequence of the decrease in relative abundance of $F$. oxysporum, or whether the Collinade-dependent decline in $F$. oxysporum opened a niche that was filled by $C$. coccodes and Pyrenochaeta lycopersici. Additional studies are needed to distinguish between these two scenarios. Such studies would also need to address the known limitations of an ITS amplicon sequencing approach, which in our specific case prevents the distinction between $F$. oxysporum f. sp. lycopersici that was experimentally added during the field trial and $F$. oxysporum that was already present in the field soil, be it $F$. oxysporum f. sp. lycopersici, $F$. oxysporum formae speciales other than $F$. oxysporum f. sp. lycopersici, or nonpathogenic $F$. oxysporum representatives. The current data also cannot distinguish between pathogenic and nonpathogenic representatives of Pyrenochaeta lycopersici or C. coccodes, although none of the root samples that were recovered from the field presented symptoms typical of corky root rot (caused by Pyrenochaeta lycopersici) or tomato brown root rot complex (resulting from infection with both Pyrenochaeta lycopersici and C. coccodes).

Application of Collinade did not result in an increase of Collimonas or Bacillus bacteria in, on, or near the roots of field-grown tomato plants (Supplementary Fig. S5). Several published studies on the impact of Bacillus-based biological controls on the bacterial community composition in the rhizosphere similarly failed to show an increase in Bacillus populations in the rhizosphere soil, on the root surface, or inside the root tissue following the application of such biological controls (Chowdhury et al. 2013; Gadhave et al. 2018; Qiao et al. 2017). There are several explanations for the inability to detect an increase in Collimonas or Bacillus populations associated with Collinade-treated roots. Firstly, the concentrations at which these bacteria were applied $\left(10^{6}\right.$ cells per $\left.\mathrm{ml}\right)$ fall several orders of magnitude below the bacterial densities that are typically found in field rhizosphere soils (Maul et al. 2014), which means that the addition of Collinade bacteria might not even be expected to significantly alter the composition of root soil microbiota at the time of application. A second explanation, which is not mutually exclusive with the first, is that Collimonas Cal35 and Bacillus QST713 are not able to persist and compete with indigenous members of the highly competitive rhizosphere soil microbial communities (Edwards et al. 2015; Johnston-Monje et al. 2017; Lundberg et al. 2012). This might be expected for $\mathrm{Cal} 35$ given that it is not native to agricultural field settings (Uroz et al. 2014) (the origin of QST713 is unknown to us). The positive effect of Collinade on $F$. oxysporum $\mathrm{f}$. sp. lycopersici-challenged tomato plants without the quantitative presence of its ingredients in the rhizosphere soil or root tissue may hold clues for the mechanism by which Collinade protects plants from $F$. oxysporum f. sp. lycopersici. Perhaps the effects of Collinade occur early in the plant-Collinade interaction or do not require the growth or sustained survival of one or both of the bacterial strains in the rhizosphere or root tissue. We expect future research exploring the synergy mechanism underlying Collinade activity to be consistent with these predictions.

\section{ACKNOWLEDGMENTS}

We thank Ag Seeds Unlimited for providing tomato transplants, Nick Bokulich and Dave Mills for BITS primers, and Justice Williams, Nhu Do, Karina Perez, Sampson Li, Ben Leacox, and Fong Xiong for their help with field work and sample processing.

\section{LITERATURE CITED}

Aleklett, K., Leff, J. W., Fierer, N., and Hart, M. 2015. Wild plant species growing closely connected in a subalpine meadow host distinct rootassociated bacterial communities. PeerJ 3:e804.

Atkinson, R. G., and Adamson, R. M. 1977. Effects of fungicides on wilt and yield of greenhouse tomatoes grown in Fusarium-infested sawdust. Can. J. Plant Sci. 57:675-680.

Axelrood, P. E., Chow, M. L., Radomski, C. C., McDermott, J. M., and Davies, J. 2002. Molecular characterization of bacterial diversity from British Columbia forest soils subjected to disturbance. Can. J. Microbiol. 48:655-674.

Ballhausen, M. B., Vandamme, P., and de Boer, W. 2016. Trait differentiation within the fungus-feeding (mycophagous) bacterial genus Collimonas. PLoS One 11:e0157552. 
Baysal, Ö., Lai, D., Xu, H.-H., Siragusa, M., Çalı̧̧kan, M., Carimi, F., Teixeira da Silva, J. A., and Tör, M. 2013. A proteomic approach provides new insights into the control of soil-borne plant pathogens by Bacillus species. PLoS One 8:e53182.

Bell, T. H., Hockett, K., Alcala-Briseno, R. I., Barbercheck, M., Beattie, G. A., et al. 2019. Manipulating wild and tamed phytobiomes: Challenges and opportunities. Phytobiomes J. 3:3-21.

Bodenhausen, N., Horton, M. W., and Bergelson, J. 2013. Bacterial communities associated with the leaves and the roots of Arabidopsis thaliana. PLoS One 8: e56329.

Bokulich, N. A., and Mills, D. A. 2013. Improved selection of internal transcribed spacer-specific primers enables quantitative, ultra-highthroughput profiling of fungal communities. Appl. Environ. Microbiol. 79: 2519-2526.

Caporaso, J. G., Kuczynski, J., Stombaugh, J., Bittinger, K., Bushman, F. D., et al. 2010. QIIME allows analysis of high-throughput community sequencing data. Nat. Methods 7:335-336.

Chelius, M. K., and Triplett, E. W. 2001. The diversity of archaea and bacteria in association with the roots of Zea mays L. Microbiol. Ecol. 41:252-263.

Chemeltorit, P. P., Mutaqin, K. H., and Widodo, W. 2017. Combining Trichoderma hamatum THSW13 and Pseudomonas aeruginosa BJ10-86: A synergistic chili pepper seed treatment for Phytophthora capsici infested soil. Eur. J. Plant Pathol. 147:157-166.

Chow, M. L., Radomski, C. C., McDermott, J. M., Davies, J., and Axelrood, P. E. 2002. Molecular characterization of bacterial diversity in Lodgepole pine (Pinus contorta) rhizosphere soils from British Columbia forest soils differing in disturbance and geographic source. FEMS Microbiol. Ecol. 42:347-357.

Chowdhury, S. P., Dietel, K., Rändler, M., Schmid, M., Junge, H., Borriss, R., Hartmann, A., and Grosch, R. 2013. Effects of Bacillus amyloliquefaciens FZB42 on lettuce growth and health under pathogen pressure and its impact on the rhizosphere bacterial community. PLoS One 8:e68818.

Clayton, E. E. 1923. The relation of temperature to the Fusarium wilt of the tomato. Am. J. Bot. 10:71-88.

Corden, M. E., and Chambers, H. L. 1966. Vascular dysfunction in Fusarium wilt of tomato. Am. J. Bot. 53:284-287.

de Boer, M., Born, P., Kindt, F., Keurentjes, J. J. B., van der Sluis, I., van Loon, L. C., and Bakker, P. A. H. M. 2003. Control of Fusarium wilt of radish by combining Pseudomonas putida strains that have different diseasesuppressive mechanisms. Phytopathology 93:626-632.

de Boer, W., Klein-Gunnewiek, P. J. A., Kowalchuk, G. A., and van Veen, J. A. 2001. Growth of chitinolytic dune soil beta-subclass Proteobacteria in response to invading fungal hyphae. Appl. Environ. Microbiol. 67: 3358-3362.

de Boer, W., Klein-Gunnewiek, P. J. A., Lafeber, P., Janse, J. D., Spit, B. E., and Woldendorp, J. W. 1998. Anti-fungal properties of chitinolytic dune soil bacteria. Soil Biol. Biochem. 30:193-203.

de Boer, W., Leveau, J. H. J., Kowalchuk, G. A., Klein-Gunnewiek, P. J. A., Abeln, E. C. A., Figge, M. J., Sjollema, K., Janse, J. D., and van Veen, J. A. 2004. Collimonas fungivorans gen. nov., sp. nov., a chitinolytic soil bacterium with the ability to grow on living fungal hyphae. Int. J. Syst. Evol. Microbiol. 54:857-864.

Deveau, A., Barret, M., Diedhiou, A. G., Leveau, J. H. J., de Boer, W., Martin, F., et al. 2015. Pairwise transcriptomic analysis of the interactions between the ectomycorrhizal fungus Laccaria bicolor S238N and three beneficial, neutral and antagonistic soil bacteria. Microbiol. Ecol. 69:146-159.

Doan, H. K., and Davis, R. M. 2014. Evaluation of Fusarium wilt resistance in six upland cotton germplasm lines. J. Cotton Sci. 18:430-434.

Doan, H. K., Perez, K., Davis, R. M., and Slaughter, D. C. 2016. Survey of molds in California processing tomatoes. J. Food Sci. 81:M2785-M2792.

Domenech, J., Reddy, M. S., Kloepper, J. W., Ramos, B., and Gutierrez-Mañero, J. 2006. Combined application of the biological product LS213 with Bacillus, Pseudomonas or Chryseobacterium for growth promotion and biological control of soil-borne diseases in pepper and tomato. BioControl 51:245-258.

Duijff, B. J., Recorbet, G., Bakker, P. A. H. M., Loper, J. E., and Lemanceau, P. 1999. Microbial antagonism at the root level is involved in the suppression of Fusarium wilt by the combination of nonpathogenic Fusarium oxysporum Fo47 and Pseudomonas putida WCS358. Phytopathology 89:1073-1079.

Edwards, J., Johnson, C., Santos-Medellin, C., Lurie, E., Podishetty, N. K., Bhatnagar, S., et al. 2015. Structure, variation, and assembly of the rootassociated microbiomes of rice. Proc. Natl. Acad. Sci. USA 112:E911-E920.

Fiddaman, P. J., and Rossall, S. 1993. The production of antifungal volatiles by Bacillus subtilis. J. Appl. Bacteriol. 74:119-126.

Fritsche, K., de Boer, W., Gerards, S., van den Berg, M., van Veen, J. A., and Leveau, J. H. J. 2008. Identification and characterization of genes underlying chitinolysis in Collimonas fungivorans Ter331. FEMS Microbiol. Ecol. 66: 123-135.

Fritsche, K., van den Berg, M., de Boer, W., van Beek, T. A., Raaijmakers, J. M., van Veen, J. A., and Leveau, J. H. J. 2014. Biosynthetic genes and activity spectrum of antifungal polyynes from Collimonas fungivorans Ter331. Environ. Microbiol. 16:1334-1345.

Gadhave, K. R., Devlin, P. F., Ebertz, A., Ross, A., and Gange, A. C. 2018. Soil inoculation with Bacillus spp. modifies root endophytic bacterial diversity, evenness, and community composition in a context-specific manner. Microbiol. Ecol. 76:741-750.

Garbeva, P., Hordijk, C., Gerards, S., and de Boer, W. 2014. Volatiles produced by the mycophagous soil bacterium Collimonas. FEMS Microbiol. Ecol. 87: 639-649.

Hakvåg, S., Fjærvik, E., Klinkenberg, G., Borgos, S. E. F., Josefsen, K. D., Ellingsen, T. E., and Zotchev, S. B. 2009. Violacein-producing Collimonas sp. from the sea surface microlayer of costal waters in Trøndelag, Norway. Mar. Drugs 7:576-588.

Hamady, M., Walker, J. J., Harris, J. K., Gold, N. J., and Knight, R. 2008. Errorcorrecting barcoded primers for pyrosequencing hundreds of samples in multiplex. Nat. Methods 5:235-237.

Heydari, A., and Pessarakli, M. 2010. A review on biological control of fungal plant pathogens using microbial antagonists. J. Biol. Sci. 10:273-290.

Hogg, A. C., Johnston, R. H., and Dyer, A. T. 2007. Applying real-time quantitative PCR to Fusarium crown rot of wheat. Plant Dis. 91:1021-1028.

Höppener-Ogawa, S., de Boer, W., Leveau, J. H. J., van Veen, J. A., de Brandt, E., Vanlaere, E., Sutton, H., Dare, D. J., and Vandamme, P. 2008. Collimonas arenae sp. nov. and Collimonas pratensis sp. nov., isolated from (semi-) natural grassland soils. Int. J. Syst. Evol. Microbiol. 58:414-419.

Jambhulkar, P. P., Sharma, P., Manokaran, R., Lakshman, D. K., Rokadia, P., and Jambhulkar, N. 2018. Assessing synergism of combined applications of Trichoderma harzianum and Pseudomonas fluorescens to control blast and bacterial leaf blight of rice. Eur. J. Plant Pathol. 152:747-757.

Janisiewicz, W. 1996. Ecological diversity, niche overlap, and coexistence of antagonists used in developing mixtures for biocontrol of postharvest diseases of apples. Phytopathology 86:473-479.

Jiménez-Fernández, D., Montes-Borrego, M., Jimenez-Diaz, R. M., NavasCortes, J. A., and Landa, B. B. 2011. I. planta and soil quantification of Fusarium oxysporum $\mathrm{f}$. sp. ciceris and evaluation of Fusarium wilt resistance in chickpea with a newly developed quantitative polymerase chain reaction assay. Phytopathology 101:250-262.

Johnston-Monje, D., Loewen, S., and Lazarovits, G. 2017. Mycobiomes of tomato plants with vine decline. Can. J. Plant Pathol. 39:184-200.

Kai, K., Sogame, M., Sakurai, F., Nasu, N., and Fujita, M. 2018. Collimonins A-D, unstable polyynes with antifungal or pigmentation activities from the fungus-feeding bacterium Collimonas fungivorans Ter331. Org. Lett. 20: 3536-3540.

Kamilova, F., Leveau, J. H. J., and Lugtenberg, B. 2007. Collimonas fungivorans, an unpredicted in vitro but efficient in vivo biocontrol agent for the suppression of tomato foot and root rot. Environ. Microbiol. 9: 1597-1603.

Knudsen, G. R., and Dandurand, L.-M. C. 2014. Ecological complexity and the success of fungal biological control agents. Adv. Agricult. 2014:542703.

Kõljalg, U., Nilsson, R. H., Abarenkov, K., Tedersoo, L., Taylor, A. F. S., Bahram, M. et al. 2013. Towards a unified paradigm for sequence-based identification of fungi. Mol. Ecol. 22:5271-5277.

Lahlali, R., Peng, G., Gossen, B. D., McGregor, L., Yu, F. Q., Hynes, R. K., Hwang, S. F., McDonald, M. R., and Boetchko, S. M. 2013. Evidence that the biofungicide Serenade (Bacillus subtilis) suppresses clubroot on canola via antibiosis and induced host resistance. Phytopathology 103:245-254.

Landa, B. B., Navas-Cortes, J. A., and Jimenez-Diaz, R. M. 2004. Influence of temperature on plant-rhizobacteria interactions related to biocontrol potential for suppression of Fusarium wilt of chickpea. Plant Pathol. 53:341-352.

Lee, S. D. 2018. Collimonas antrihumi sp. nov., isolated from a natural cave and emended description of the genus Collimonas. Int. J. Syst. Evol. Microbiol. 68:2448-2453.

Lemanceau, P., Bakker, P. A. H. M., de Kogel, W. J., Alabouvette, C., and Schippers, B. 1992. Effect of pseudobactin-358 production by Pseudomonas putida WCS358 on suppression of Fusarium wilt of carnations by nonpathogenic Fusarium oxysporum Fo47. Appl. Environ. Microbiol. 58: 2978-2982.

Leveau, J. H. J., Gerards, S., de Boer, W., and van Veen, J. A. 2004. Phylogenyfunction analysis of (meta)genomic libraries: Screening for expression of ribosomal RNA genes by large-insert library fluorescent in situ hybridization (LIL-FISH). Environ. Microbiol. 6:990-998. 
Leveau, J. H. J., Gerards, S., Fritsche, K., Zondag, G., and van Veen, J. A. 2006. Genomic flank-sequencing of plasposon insertion sites for rapid identification of functional genes. J. Microbiol. Methods 66:276-285.

Leveau, J. H. J., and Lindow, S. E. 2005. Utilization of the plant hormone indole3-acetic acid for growth by Pseudomonas putida strain 1290. Appl. Environ. Microbiol. 71:2365-2371.

Leveau, J. H. J., Uroz, S., and de Boer, W. 2010. The bacterial genus Collimonas: Mycophagy, weathering, and other adaptive solutions to life in oligotrophic soil environments. Environ. Microbiol. 12:281-292.

Liu, K., McInroy, J. A., Hu, C.-H., and Kloepper, J. W. 2018. Mixtures of plantgrowth-promoting rhizobacteria enhance biological control of multiple plant diseases and plant-growth promotion in the presence of pathogens. Plant Dis. 102:67-72.

Lundberg, D. S., Lebeis, S. L., Paredes, S. H., Yourstone, S., Gehring, J., Malfatti, S., et al. 2012. Defining the core Arabidopsis thaliana root microbiome. Nature 488:86-90.

Maharaj, N. N., Miyao, E. M., Davis, R. M., Uroz, S., and Leveau, J. H. J. 2018. Impact of soil chemistry, nutrient supplements, and fungicides on the health and yield of field-grown processing tomatoes. Eur. J. Plant Pathol. 152: 855-868.

Männistö, M. K., and Häggblom, M. M. 2006. Characterization of psychrotolerant heterotrophic bacteria from Finnish Lapland. Syst. Appl. Microbiol. 29:229-243.

Marian, M., Morita, A., Koyama, H., Suga, H., and Shimizu, M. 2019. Enhanced biocontrol of tomato bacterial wilt using the combined application of Mitsuaria sp. TWR114 and nonpathogenic Ralstonia sp. TCR112. J. Gen. Plant Pathol. 85:142-154.

Maul, J. E., Buyer, J. S., Lehman, R. M., Culman, S., Blackwood, C. B., Roberts, D. P., Zasada, I. A., and Teasdale, J. R. 2014. Microbial community structure and abundance in the rhizosphere and bulk soil of a tomato cropping system that includes cover crops. Appl. Soil Ecol. 77:42-50.

Mela, F., Fritsche, K., Boersma, H., van Elsas, J. D., Bartels, D., Meyer, F., de Boer, W., van Veen, J. A., and Leveau, J. H. J. 2008. Comparative genomics of the pIPO2/pSB102 family of environmental plasmids: sequence, evolution, and ecology of pTer331 isolated from Collimonas fungivorans Ter331. FEMS Microbiol. Ecol. 66:45-62.

Mela, F., Fritsche, K., de Boer, W., van den Berg, M., van Veen, J. A., Maharaj, N. N., et al. 2012. Comparative genomics of bacteria from the genus Collimonas: Linking (dis)similarities in gene content to phenotypic variation and conservation. Environ. Microbiol. Rep. 4:424-432.

Mela, F., Fritsche, K., de Boer, W., van Veen, J. A., de Graaff, L. H., van den Berg, M., and Leveau, J. H. J. 2011. Dual transcriptional profiling of a bacterial/fungal confrontation: Collimonas fungivorans versus Aspergillus niger. ISME J. 5:1494-1504.

Mendis, H. C., Thomas, V. P., Schwientek, P., Salamzade, R., Chien, J. T., Waidyarathne, P., Kloepper, J., and De La Fuente, L. 2018. Strain-specific quantification of root colonization by plant growth promoting rhizobacteria Bacillus firmus I-1582 and Bacillus amyloliquefaciens QST713 in non-sterile soil and field conditions. PLoS One 13:e0193119.

Miyao, G. 2013. 2012 Processing tomato variety trials. University of California Cooperative Extension, Woodland, CA. https://vric.ucdavis.edu/pdf/ TOMATO/ProcTomatoTrials2012YoloSolanoSac.pdf

O’Donnell, K., Kistler, H. C., Cigelnik, E., and Ploetz, R. C. 1998. Multiple evolutionary origins of the fungus causing Panama disease of banana: Concordant evidence from nuclear and mitochondrial gene genealogies. Proc. Natl. Acad. Sci. USA 95:2044-2049.

Offre, P., Pivato, B., Mazurier, S., Siblot, S., Berta, G., Lemanceau, P., et al. 2008. Microdiversity of Burkholderiales associated with mycorrhizal and nonmycorrhizal roots of Medicago truncatula. FEMS Microbiol. Ecol. 65: 180-192.

Pandin, C., Le Coq, D., Deschamps, J., Vedie, R., Rousseau, T., Aymerich, S., and Briandet, R. 2018. Complete genome sequence of Bacillus velezensis QST713: A biocontrol agent that protects Agaricus bisporus crops against the green mould disease. J. Biotechnol. 278:10-19.

Panebianco, S., Vitale, A., Polizzi, G., Scala, F., and Cirvilleri, G. 2015. Enhanced control of postharvest citrus fruit decay by means of the combined use of compatible biocontrol agents. Biol. Control 84:19-27.

Park, C. S., Paulitz, T. C., and Baker, R. 1988. Biocontrol of Fusarium wilt of cucumber resulting from interactions between Pseudomonas putida and nonpathogenic isolates of Fusarium oxysporum. Phytopathology 78 : 190-194.

Pierson, E. A., and Weller, D. M. 1994. Use of mixtures of fluorescent pseudomonads to suppress take-all and improve the growth of wheat. Phytopathology 84:940-947.
Postma, J., Nijhuis, E. H., and Sommeus, E. 2010. Selection of phosphorus solubilizing bacteria with biocontrol potential for growth in phosphorus rich animal bone charcoal. Appl. Soil Ecol. 46:464-469.

Postma, J., Schilder, M. T., Bloem, J., and van Leeumen-Haagsma, W. K. 2008. Soil suppressiveness and functional diversity of the soil microflora in organic farming systems. Soil Biol. Biochem. 40:2394-2406.

Qiao, J., Yu, X., Liang, X., Liu, Y., Borriss, R., and Liu, Y. 2017. Addition of plantgrowth-promoting Bacillus subtilis PTS-394 on tomato rhizosphere has no durable impact on composition of root microbiome. BMC Microbiol. 17:131.

R Core Team. 2014. R: A Language and Environment for Statistical Computing. R Foundation for Statistical Computing, Vienna, Austria.

Rahman, S. F. S. A., Singh, E., Pieterse, C. M. J., and Schenk, P. M. 2018. Emerging microbial biocontrol strategies for plant pathogens. Plant Sci. 267: 102-111.

Rania, A. B. A., Jabnoun-Khiareddine, H., Nefzi, A., Mokni-Tlili, S., and Daami-Remadi, M. 2016. Endophytic bacteria from Datura metel for plant growth promotion and bioprotection against Fusarium wilt in tomato. Biocontrol Sci. Technol. 26:1139-1165.

Rastogi, G., Tech, J. J., Coaker, G. L., and Leveau, J. H. J. 2010. A PCR-based toolbox for the culture-independent quantification of total bacterial abundances in plant environments. J. Microbiol. Methods 83:127-132.

Rilling, J. I., Acuna, J. J., Nannipieri, P., Cassan, F., Maruyama, F., and Jorquera, M. A. 2019. Current opinion and perspectives on the methods for tracking and monitoring plant growth-promoting bacteria. Soil Biol. Biochem. 130:205-219.

Schwarz, D., Thompson, A. J., and Kläring, H. P. 2014. Guidelines to use tomato in experiments with a controlled environment. Front. Plant Sci. 5:625.

Senechkin, I. V., van Overbeek, L. S., Er, H. L., de Vos, O., and van Bruggen, A. H. C. 2013. Interaction of Collimonas strain IS343 with Rhizoctonia solani at low carbon availability $i$. vitro and in soil. Eur. J. Plant Pathol. 136:789-802.

Shcherbakov, A. V., Bragina, A. V., Kuzmina, E. Y., Berg, C., Muntyan, A. N., Makarova, N. M., Malfanova, N. V., Cardinale, M., Berg, G., Chebotar, V. K., and Tikohonovich, I. A. 2013. Endophytic bacteria of Sphagnum mosses as promising objects of agricultural microbiology. Microbiology 82:306-315.

Song, C. X., Schmidt, R., de Jager, V., Krzyzanowska, D., Jongedijk, E., Cankar, K., et al. 2015. Exploring the genomic traits of fungus-feeding bacterial genus Collimonas. BMC Genomics 16:1103.

Tayal, P., Kapoor, R., and Bhatnagar, A. K. 2011. Functional synergism among Glomus fasciculatum, Trichoderma viride, and Pseudomonas fluorescens on Fusarium wilt in tomato. J. Plant Pathol. 93:745-750.

Uroz, S., Calvaruso, C., Turpault, M. P., Sarniguet, A., de Boer, W., Leveau, J. H. J., et al. 2009. Efficient mineral weathering is a distinctive functional trait of the bacterial genus Collimonas. Soil Biol. Biochem. 41:2178-2186.

Uroz, S., Tech, J. J., Sawaya, N. A., Frey-Klett, P., and Leveau, J. H. J. 2014. Structure and function of bacterial communities in ageing soils: Insights from the Mendocino ecological staircase. Soil Biol. Biochem. 69:265-274.

Validov, S. Z., Kamilova, F. D., and Lugtenberg, B. J. J. 2011. Monitoring of pathogenic and non-pathogenic Fusarium oxysporum strains during tomato plant infection. Microbiol. Biotechnol. 4:82-88.

Vrisman, C. M., Testen, A. J., Elahi, F., and Miller, S. A. 2016. First report of tomato brown root rot complex caused by Colletotrichum coccodes and Pyrenochaeta lycopersici in Ohio. Plant Dis. 101:247.

Wickham, H. 2009. Ggplot2: Elegant Graphics for Data Analysis. Springer Verlag, New York.

Wickham, H., and Francois, R. 2015. dplyr: A grammar of data manipulation, R package version 0.4.1.

Woźniak, M., Gałązka, A., Grządziel, J., and Głodowska, M. 2018. The identification and genetic diversity of endophytic bacteria isolated from selected crops. J. Agric. Sci. 156:547-556.

Wright, S. J. L., and Thompson, R. J. 1985. Bacillus volatiles antagonize cyanobacteria. FEMS Microbiol. Lett. 30:263-267.

Wu, H., Li, J., Liu, W., Bai, X., Liu, D., and Zhang, J. 2016. Identification and characterization of ZL261, a novel Collimonas pratensis strain with antagonistic activity toward Monilinia fructicola. Sci. China Life Sci. 59: 1345-1347.

Wu, J. J., de Jager, V. C., Deng, W. L., and Leveau, J. H. J. 2015. Finished genome sequence of Collimonas arenae Cal35. Genome Announc. 3: e01408-e01414.

Xu, X. M., Jeffires, P., Pautasso, M., and Jeger, M. J. 2011. Combined use of biocontrol agents to manage plant diseases in theory and practice. Phytopathology 101:1024-1031.

Zhang, H., Zheng, R., Zhang, T., Dong, D., Liu, T., Zhao, J., Tian, Z., Liu, W., Luo, L., and Wu, H. 2018. Efficient transformation and expression of Vitreoscilla haemoglobin in the biological control bacterium Collimonas pratensis ZL261. Biocontrol Sci. Technol. 28:786-795. 